ORIGINAL ARTICLE

\title{
Frequency of Most Prevalent Bacteria in Wound of Diabetic Foot Ulcers and their Antimicrobial Susceptibility to Different Antibiotics
}

\author{
ASHFAQ NASIR ${ }^{1}$, MUHAMMAD NAJAM IQBAL ${ }^{2}$, GHULAM HASSAN ${ }^{3}$, MUHAMMAD ARSHAD ABBAS $^{4}$, HAFIZ JAWAD \\ ABDUL RAHEEM ${ }^{5}$, ABRAR ZAHID ${ }^{6}$ \\ ${ }^{1}$ Assistant Professor of Surgery, Surgical, Services Hospital, Lahore \\ ${ }^{2}$ Assistant Professor of Surgery, Quaid-e-Azam Medical College/ Bahawal Victoria Hospital Bahawalpur \\ ${ }^{3}$ Assistant Professor of Surgery, Allama lqbal Medical College Lahore \\ ${ }^{4}$ Associate Professor of Surgery, Shahida Islam Medical College Lodhran \\ ${ }^{5}$ Senior Registrar Surgery, Services Hospital, Lahore. \\ ${ }^{6}$ Senior Registrar Surgery, Ghurki Trust Teaching Hospital, Lahore \\ Correspondence to Dr Muhammad Arshad Abbas...Email:drarshadabbas137@yahoo.com, Tel. 0300-4455969
}

\begin{abstract}
Background: Most of the diabetic patients present as diabetic foot in surgical outdoor and emergency department. Diabetic Foot infections are common and take long duration to be treated. Both Gram positive and Gram negative aerobic bacteria are involved in diabetic foot infection.

Aim: To determine the frequency of most prevalent bacteria in wound of diabetic foot ulcers and to determine the antimicrobial susceptibility of isolated bacteria from diabetic foot ulcers so that an empirical antibiotics can be started before the report of culture and sensitivity.

Methods: This cross sectional study was conducted in surgical unit 1 of Bahawal Victoria Hospital (BVH) Bahawalpur from 01-08-2020 to 31-07-2021. This study was conducted on 145 patients with diabetic foot ulcer from outdoor and emergency department of BVH. Data about patient's demography, duration of diabetes, duration of DFUs, type of pathogen and its antibiotic susceptibility was entered on a proforma. Pus sample was obtained from wound under aseptic measures. Culture sensitivity to assess presence of type of pathogen and its antibiotic susceptibility of all the samples was done from the pathology department of the hospital.

Results: The mean age of patients was $52.02 \pm 10.14$ years. There were $77(53.1 \%)$ males and $68(46.9 \%)$ females.

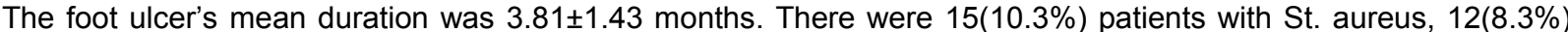
with E.coli, 12(8.3\%) with Proteus mirabilis, 15(10.3\%) with P. aeruginosa, 12(8.3\%) with Enterobacter spp., 9(6.2\%) with Morganella spp., 19(13.1\%) with P. vulgaris, 18(12.4\%) with P. Mirabilis, 16(11\%) with K. pneumonia and $17(11.75)$ with Morganella pathogen in this study. There were $74(51 \%)$ patients sensitive to Amikacin, 73(50.3\%) sensitive to Amoxicillin, 66(45.5\%) sensitive to Aztreonam, $74(51 \%)$ sensitive to Ceftriaxone, $75(51.7 \%)$ sensitive to Cefuroxime and 68(49.6\%) sensitive to Cephazolin.

Conclusion: The most frequent organisms in DFUs, regardless of age, gender and comorbidity, were P. vulgaris, St. aureus and P. aeruginosa. The most sensitive antibiotic in these ulcers was Piperacillin and Meropenem and the most resistant was Cephazolin.

Keywords: Diabetic Foot Ulcers, Antimicrobial Susceptibility, St. aureus, P. vulgaris, P. aeruginosa, Piperacillin
\end{abstract}

\section{INTRODUCTION}

Most of the patients with diabetic foot infections need hospitalization ${ }^{1}$. Approximately half of the patients who have foot ulcers develop an infection ${ }^{2}$. Main cause of patient morbidity are these infections and if not treated in time with proper antibiotic can lead to lower limb amputation $^{3}$. In Pakistan $90 \%$ of patients with foot ulcer ndergo amputation ${ }^{4}$. Both Gram positive and Gram negative aerobic bacteria are implicated in diabetic foot infections ${ }^{5}$. In some studies gram positive organisms and in some studies gram negative bacteria

are the main causative pathogens ${ }^{6}$. Resistance to antibiotics is the main problem in the treatment of diabetic foot infection as shown in different studies?

In a study reported by Alavi SM, Khosravi AD et al, staphylococcus aureus was most frequent $(23.16 \%$ ) followed by E. coli $17.89 \%$ and Klebsiella $12.63 \%$. The organisms were most sensitive to Meropenem in (95\%) patients and most resistant to Cotrimoxazole $(84 \%)^{8}$.

Received on 12-04-2021

Accepted on 24-08-2021
Rationale of this study is to assess the most prevalent pathogen and its antibiotic sensitivity pattern involved in DFUs. Diabetic foot infections are difficult to manage .Treatment of diabetic foot infections according to culture and sensitivity will help in early healing of wounds and reduces chances of amputation.

This study is planned to assess the most common pathogen involved and to check its sensitivity pattern in order to improve the practice and predict the pathogen involved in DFUs and manage the patients accordingly.

\section{MATERIAL AND METHODS}

Total 145 patients were included in the study from surgical Unit 1, Bahawal Victoria Hospital Bahawalpur from 01-082020 to 31-07-2021 after approval from ethical committee. Informed consent was taken from every patient. Data about patient's demography duration of diabetes, duration of DFUs, type of pathogen and its antibiotic susceptibility was entered on a proforma. Pus sample was obtained from wound under aseptic measures under local anesthesia. Culture sensitivity to assess presence of type of pathogen and its antibiotic susceptibility of all the samples was done 
from the pathology department of the hospital. SPSS version 21 was used for statistical analysis. Mean and standard deviation of age, body mass index, duration of diabetes and foot ulcers were calculated. Frequency and percentage of Qualitative Data like gender, type of bacteria and susceptibility to antibiotics were calculated. Patients were stratified according to age, gender, duration of diabetes and foot ulcers. Post stratification, type of pathogen was compared in stratified patients. The study was considered significant if $P$-value $\leq 0.05$.

\section{RESULTS}

The mean age of the patients was $52.02 \pm 10.14$ years. The minimum age was 35 years and maximum was 70 years. There were $77(53.1 \%)$ males and $68(46.9 \%)$ females in our study. The mean duration of diabetes was $4.59 \pm 1.36$ years. The minimum duration of diabetes was 2 years and maximum was 7 years. The mean duration for foot ulcer was $3.81 \pm 1.43$ months. The minimum duration of foot ulcer was 2 months and maximum was 6 months. Frequency of pathogens according to gender and age groups is shown in table 1. Association between type of pathogen and age groups was significant as the $p$-value was $p$-value: 0.025 . Association between type of pathogen and gender was not significant ( $p$-value: 0.29).

The susceptibility of antibiotics to microorganism in patients of diabetic foot ulcers is shown in table 1.

There was no significant association between type of pathogen and duration of foot ulcer as the $p$-value was not significant ( $p$-value 0.74).

Table1: Frequency of type of pathogens

\begin{tabular}{|c|c|c|c|c|c|c|c|}
\hline \multirow[t]{2}{*}{ Organism } & \multicolumn{2}{|c|}{ Gender } & \multirow[t]{2}{*}{ Frequency } & \multicolumn{3}{|c|}{ Age groups } & \multirow[t]{2}{*}{ \%age } \\
\hline & Male & Female & & $35-46$ & $47-58$ & $59-70$ & \\
\hline St. Aureus & 7 & 8 & 15 & 5 & 2 & 8 & $10.3 \%$ \\
\hline E. coli & 6 & 6 & 12 & 5 & 5 & 2 & $8.3 \%$ \\
\hline Proteus mirabilis & 9 & 3 & 12 & 1 & 6 & 5 & $8.3 \%$ \\
\hline P. aeruginosa & 8 & 7 & 15 & 6 & 5 & 4 & $10.3 \%$ \\
\hline Enterobacterspp. & 3 & 9 & 12 & 3 & 6 & 3 & $8.3 \%$ \\
\hline Morganella spp. & 6 & 3 & 9 & 4 & 3 & 2 & $6.2 \%$ \\
\hline P. vulgaris & 14 & 5 & 19 & 9 & 5 & 5 & $13.1 \%$ \\
\hline P. Mirabilis & 18 & 0 & 18 & 5 & 9 & 4 & $12.4 \%$ \\
\hline K. pneumonia & 9 & 7 & 16 & 10 & 0 & 6 & $11.0 \%$ \\
\hline Morganella & 7 & 10 & 17 & 6 & 3 & 8 & $11.7 \%$ \\
\hline Total & 77 & 68 & 145 & 54 & 44 & 47 & 100 \\
\hline
\end{tabular}

Table 2: Susceptibility Of Antibiotics

\begin{tabular}{|l|l|l|l|l|l|}
\hline Antibiotic & Sensitive & $\%$ age & Resistance & $\%$ age & Total \\
\hline Amikacin & 74 & 51 & 71 & 49 & 145 \\
\hline Amoxicillin & 73 & 50.3 & 72 & 49.7 & 145 \\
\hline Aztreonam & 76 & 52.45 & 69 & 47.55 & 145 \\
\hline Ceftriaxone & 74 & 51 & 71 & $49 \%$ & 145 \\
\hline Cefuroxime & 75 & 51.7 & 70 & 48.3 & 145 \\
\hline Cephazolin & 68 & 46.89 & 77 & 53.11 & 145 \\
\hline Ciprofloxacin & 70 & 48.3 & 75 & 51.7 & 145 \\
\hline Clindamycin & 75 & 51.7 & 70 & 48.3 & 145 \\
\hline Cloxacillin & 79 & 54.48 & 66 & 45.52 & 145 \\
\hline Cotrimoxazole & 79 & 54.48 & 66 & 45.52 & 145 \\
\hline Gentamycin & 68 & 46.89 & 77 & 53.11 & 145 \\
\hline Meropenem & 60 & 41.37 & 68 & 46.89 & 145 \\
\hline Piperacillin & 87 & $60 \%$ & 57 & 40 & 145 \\
\hline Vancomycin & 72 & $49.3 \%$ & 73 & 50.7 & 145 \\
\hline
\end{tabular}

Table 3: Types of bacteria According To Duration Of Foot Ulcers

\begin{tabular}{|l|c|c|c|}
\hline \multirow{2}{*}{ Pathogen } & \multicolumn{2}{|c|}{ Duration of foot ulcer } & \multirow{2}{*}{ Total } \\
\cline { 2 - 3 } & $\mathbf{2 - 4}$ & $\mathbf{5 - 7}$ & \\
\hline St. Aureus & $11(12.4 \%)$ & $4(7.1 \%)$ & $15(10.3 \%)$ \\
\hline E. coli & $6(6.7 \%)$ & $6(10.7 \%)$ & $12(8.3 \%)$ \\
\hline Proteus mirabilis & $8(9.0 \%)$ & $4(7.1 \%)$ & $12(8.3 \%)$ \\
\hline P. aeruginosa & $9(10.1 \%)$ & $6(10.7 \%)$ & $15(10.3 \%)$ \\
\hline Enterobacter spp. & $8(9.0 \%)$ & $4(7.1 \%)$ & $12(8.3 \%)$ \\
\hline Morganella spp. & $6(6.7 \%)$ & $3(5.4 \%)$ & $9(6.2 \%)$ \\
\hline P. vulgaris & $12(13.5 \%)$ & $7(12.5 \%)$ & $19(13.1 \%)$ \\
\hline P. Mirabilis & $13(14.6 \%)$ & $5(8.9 \%)$ & $18(12.4 \%)$ \\
\hline K. pneumonia & $9(10.1 \%)$ & $7(12.5 \%)$ & $16(11.0 \%)$ \\
\hline Morganella & $7(7.9 \%)$ & $10(17.9 \%)$ & $17(11.7 \%)$ \\
\hline Total & $89(100 \%)$ & $56(100 \%)$ & $145(100 \%)$ \\
\hline
\end{tabular}

\section{DISCUSSION}

Foot ulceration in diabetic patients can involve skin, subcutaneous tissue and deeper structures ${ }^{9}$. According to Nageen et al $2016^{8}$ their study reported that males presented more with diabetic foot than females. These findings are similar to the findings of our study as in our study the frequency of diabetic foot was little higher in males $(53.1 \%)$ as compare to females $(46.9 \%)$ these findings are consistent to a study done in Karachi. ${ }^{10}$ and in Iran ${ }^{11}$. According to Nageen et al the mean age of the patients at presentation was 52.74 years whereas in our study the mean age of the patients was 52.02 years which is almost similar with the findings of the study mentioned above. One study ${ }^{8}$ reported that the most frequent organisms isolated were Staphylococcus (S.) aureus, E coli and then Klebsiella whereas in our study the most common organism isolated were $P$. vulgaris $(13.1 \%), P$. Mirabilis (12.4\%), Morganella (11.7\%) and then $\mathrm{K}$. pneumonia(11\%).According to a study in India in 2006, S. aureus was the commonest organism, then Proteus and then E. coli ${ }^{12}$ Similiar results were reported in the Netherlands $^{13}$ and in a local study done in Peshawar Pakistan ${ }^{14}$. However according to a study conducted in China on diabetic foot infections, Proteus was the most prevalent followed by $\mathrm{E}$. coli ${ }^{15}$ while a study in India showed that $\mathrm{E}$. coli to be the most prevalent with Staphylococcus aureus as the second commonest organism ${ }^{16}$ but in our study, P. vulgaris is more prevalent than St. aureus and P. aeruginosa in diabetic foot. The gram-negative bacteria were commoner than gram positive ones similar to a study in India ${ }^{16}$.

According to the findings of one more study ${ }^{8}$ the most effective antibiotic to all organisms was Meropenem, as in another study done on the efficacy of Meropenem on DFU 17 whereas in our study the most sensitive antibiotic was Piperacillin. The findings of studies also reported that the next were Amikacin, and Gentamycin. While in our study the next were Cotrimoxazole and Cloxacillin. According to Anvarinejad et $\mathrm{al}^{18}$ and majority of studies, 
Staphylococcus spp. was the most frequent pathogens isolated $^{19}$.

Enterococci are more common in foot ulcers, but their mechanism of action is not clear ${ }^{20}$. The findings of other studies $^{8,21}$ also reported that Cotrimoxazole was the most resistant antibiotic. In another study the most resistant antibiotic was gentamicin than Cephazolin ${ }^{22}$. There is growing resistance against Cephalosporin and Cotrimoxazole. Staphylococcus aureus was prevalent in both the genders and in all age groups implying no gender or age difference in the frequency of organisms ${ }^{20}$. Combination of these antibiotics was not useful ${ }^{23}$ Considering the results, it can be suggested that the most suitable antibiotic for Enterobacteriaceae isolates are, colistin, carbapenem, polymyxin B and amikacin. Linezolid and vancomycin were less resistance to gram positive $\operatorname{cocci}^{24}$.

\section{CONCLUSION}

The most frequent organisms in DFUs, regardless of age, gender and comorbidity, were P. vulgaris, St. aureus and $P$. aeruginosa. The most sensitive antibiotic in these ulcers was Piperacillin and Meropenem and the most resistant was Cephazolin. Males presented more with DFUs than females.

Contribution of authors: AN: Literature Review. MNI: Data analysis, GH: Data analysis, MAA: Discussion, HJAR: Data collection:

Conflict of interest: Nil

\section{REFERENCES}

1. Collaboration NRF. Worldwide trends in diabetes since 1980: a pooled analysis of 751 population-based studies with 4.4 million participants. The Lancet 2016; 387(10027):1513-30.

2. Jaacks LM, Siegel KR, Gujral UP, Narayan KV. Type 2 diabetes: a 21st century epidemic. Best Practice \& Research Clinical Endocrinology \& Metabolism 2016;30(3):331-43.

3. Guariguata L, Whiting DR, Hambleton I, Beagley J, Linnenkamp U, Shaw JE. Global estimates of diabetes prevalence for 2013 and projections for 2035. Diabetes research and clinicalpractice2014;103(2):137-49.

4. Rehman R, Malik FR, Rehman Z. A comparative study on diabetic foot ulcers leading to amputations. Journal of Postgraduate Medical Institute (Peshawar-Pakistan) 2018;32(1).

5. Noor S, Zubair M, Ahmad J. Diabetic foot ulcer-a review on pathophysiology, classification and microbial etiology. Diabetes \& Metabolic Syndrome: Clinical Research \& Reviews 2015;9(3):192-9.

6. Uçkay I, Gariani K, Pataky Z, Lipsky BA. Diabetic foot infections: state-of-the-art. Diabetes, Obesity and Metabolism 2014;16(4):305-16.

7. Alavi SM, Khosravi AD, Sarami A, Dashtebozorg A, Montazeri EA. Bacteriologic study of diabetic foot ulcer. Foot 2007;23(5):681-4.

8. Nageen A. The most prevalent organism in diabetic foot ulcers and its drug sensitivity and resistance to different standard antibiotics. JCPSP; 2016;26(4):293-6.
9. Mendes J, Neves J. Diabetic foot infections: current diagnosis and treatment. Journal of Diabetic Foot Complications 2012:26-45.

10. Riaz M, Miyan Z, Zaidi SI, Alvi SFD, Fawwad A, Ahmadani MY, et al. Characteristics and outcomes of subjects with diabetic foot ulceration. Diabetes care 2012;35(9):e63-e.

11. Al-Rubeaan K, Al Derwish M, Ouizi S, Youssef AM, Subhani $\mathrm{SN}$, Ibrahim HM, et al. Diabetic foot complications and their risk factors from a large retrospective cohort study. PloS one2015;10(5)

12. Gadepalli R, Dhawan B, Sreenivas V, Kapil A, Ammini A, Chaudhry R. A clinico-microbiological study of diabetic foot ulcers in an Indian tertiary care hospital. Diabetes care 2006;29(8):1727-32.

13. Bakker K, Apelqvist J, Schaper NC, Board IWGotDFE. Practical guidelines on the management and prevention of the diabetic foot 2011. Diabetes/metabolism research and reviews 2012;28:225-31.

14. Aamir AH, Nasir A, Jadoon MZ, Mehmood K, Ali SS. Diabetic foot infections and their management in a tertiary care hospital. Journal of Ayub Medical College Abbottabad 2011;23(1):58-62.

15. Lipsky BA, Berendt AR, Deery HG, Embil JM, Joseph WS, Karchmer AW, et al. Diagnosis and treatment of diabetic foot infections. Clinical Infectious Diseases 2004:885-910.

16. Bengalorkar GM, Kumar T. Culture and sensitivity pattern of micro-organism isolated from diabetic foot infections in a tertiary care hospital. Int J Cur Biomed Phar Res 2011;1(2):34-40.

17. Fish DN. Meropenem in the treatment of complicated skin and soft tissue infections. Therapeutics and clinical risk management 2006;2(4):401.

18. Anvarinejad M, Pouladfar $G$, Japoni A, Bolandparvaz $S$, Satiary $Z$, Abbasi $P$, et al. Isolation and antibiotic susceptibility of the microorganisms isolated from diabetic foot infections in Nemazee Hospital, Southern Iran. Journal of pathogens 2015;2015.

19. Amini M, Davati A, Piri M. Determination of the resistance pattern of prevalent aerobic bacterial infections of diabetic foot ulcer. Iranian Journal of Pathology 2013;8(1):21-6.

20. Higuita NIA, Huycke MM. Enterococcal disease, epidemiology, and implications for treatment. Enterococci: From commensals to leading causes of drug resistant infection [Internet]: Massachusetts Eye and Ear Infirmary; 2014.

21. Anvarinejad M, Pouladfar G, Japoni A, Bolandparvaz S, Satiary Z, Mardaneh J. Diabetic Foot Infections: antibiotic susceptibility patterns and determination of antibiotic crossresistance in clinical isolates of Enterococcus species during 2012-2014 in Shiraz, Iran. Archives of Pediatric Infectious Diseases 2017;5(2).

22. Hartemann-Heurtier A, Robert J, Jacqueminet S, Ha Van G, Golmard J, Jarlier V, et al. Diabetic foot ulcer and multidrugresistant organisms: risk factors and impact. Diabetic Medicine 2004;21(7):710-5.

23. Oliveira AFd, Oliveira Filho Hd. Microbiological species and antimicrobial resistance profile in patients with diabetic foot infections. Jornal Vascular Brasileiro 2014;13(4):289-93.

24. Siami G, Christou N, Eiseman I, Tack K. Clinafloxacin versus piperacillin-tazobactam in treatment of patients with severe skin and soft tissue infections. Antimicrobial agents and chemotherapy 2001;45(2):525-31. 